\title{
Comparative Technical-and-Economical Evaluation of Production Costs of Coagulant from Technical-Grade Aluminum Hydroxide and Hydroxide Sluge
}

\author{
Tuzhilin Aleksey Sergeevich, Balmaev Boris Grigorievich, and Vetchinkina \\ Tatiana Nikolaevna \\ Baikov Institute of Metallurgy \& Materials Science (IMET RAS), Moscow, Russia
}

\section{Abstract}

A comparative techno-economic estimate of the cost of HOAC producing from technical aluminum hydroxide and hydroxide sludge showed that the cost of HOAC would be decreased by $11 \%$ by using a hydroxide precipitate. The cost of operation on the hydroxide precipitate will decrease by $17.3 \%$ provided the storage vessel is converted into a reactor to neutralize the acid solution of HOAC. This is possible due to doubling

Corresponding Author: Tuzhilin Aleksey Sergeevich dkdm@mail.ru

Published: 31 December 2020

Publishing services provided by Knowledge E

(c) Tuzhilin Aleksey Sergeevich et al. This article is distributed under the terms of the

Commons Attribution License, which permits unrestricted use and redistribution provided that the original author and source are credited.

Selection and Peer-review under the responsibility of the TECHNOGEN-2019 Conference Committee.

\section{G OPEN ACCESS}

Millions tons of aluminum-containing waste are formed at the plants of non-ferrous metallurgy as well as in the other industries. These wastes are mainly sent to dumps, thus severely deteriorating the environmental situation of the surrounding areas. Among these are wastes of radio components plants - hydroxide precipitates released during electrolytic etching aluminum products [1]. They are based on hydroxide, aluminum chloride and sodium sulfate.

In hydrochloric acid only as-deposited aluminum hydroxide dissolves quickly enough, it can be obtained by neutralization of $\mathrm{AlCl}_{3}$ solution with ammoniaca liquor until slightly alkaline reaction, reaction of $\mathrm{AlCl}_{3}$ with $\mathrm{NaAlO}_{2}$, neutralization of aluminate solution with nitrogen acid, low-temperature carbonization of sodium aluminate solution [2, 3]. When producing hydroxyaluminum chloride (HOAC) coagulant technical aluminum hydroxide is used, it dissolves extremely slowly in $27 \%$ hydrochloric acid, up to 12 hours at $100-105^{\circ} \mathrm{C}$. Experimental studies of the hydroxide precipitate with hydrochloric acid interaction showed that it is completely soluble in $27 \%$ hydrochloric acid during 6 hours to form a low-basic hydroxyaluminum chloride. One of the best examples of the effective 
use of aluminum-containing waste is the replacement of technical aluminum hydroxide with a hydroxide precipitate for producing coagulants.

The results of comparative technical-and-economic evaluation of the cost of HOAC production using technical aluminum hydroxide and hydroxide precipitate are given in table 1. We use the production technology of HOAC from technical aluminum hydroxide and hydrochloric acid, utilised at the OOO Severkhimprom enterprise [4] as a guide. Two versions for organizing HOAC production from hydroxide sludge on existing technological equipment were considered: 1st - without an increase in HOAC production; 2nd - with an increase in production from 5 up to 10 thousand tons / year. The existing hardware setup (see Figure 1) consists of six identical tanks with the vapor blanket, three tanks are equipped with mixers $1_{1}, 1_{2}, 3$.

The reactors $1_{1}$ and $1_{2}$ have aluminum hydroxide and hydrochloric acid feeding systems and vapour recovery system. The reactor 3 has a chemical feeder of a neutralizing reagent (natron). The remaining three reactors $(2,4,5)$ are equipped with transfer pumps only.

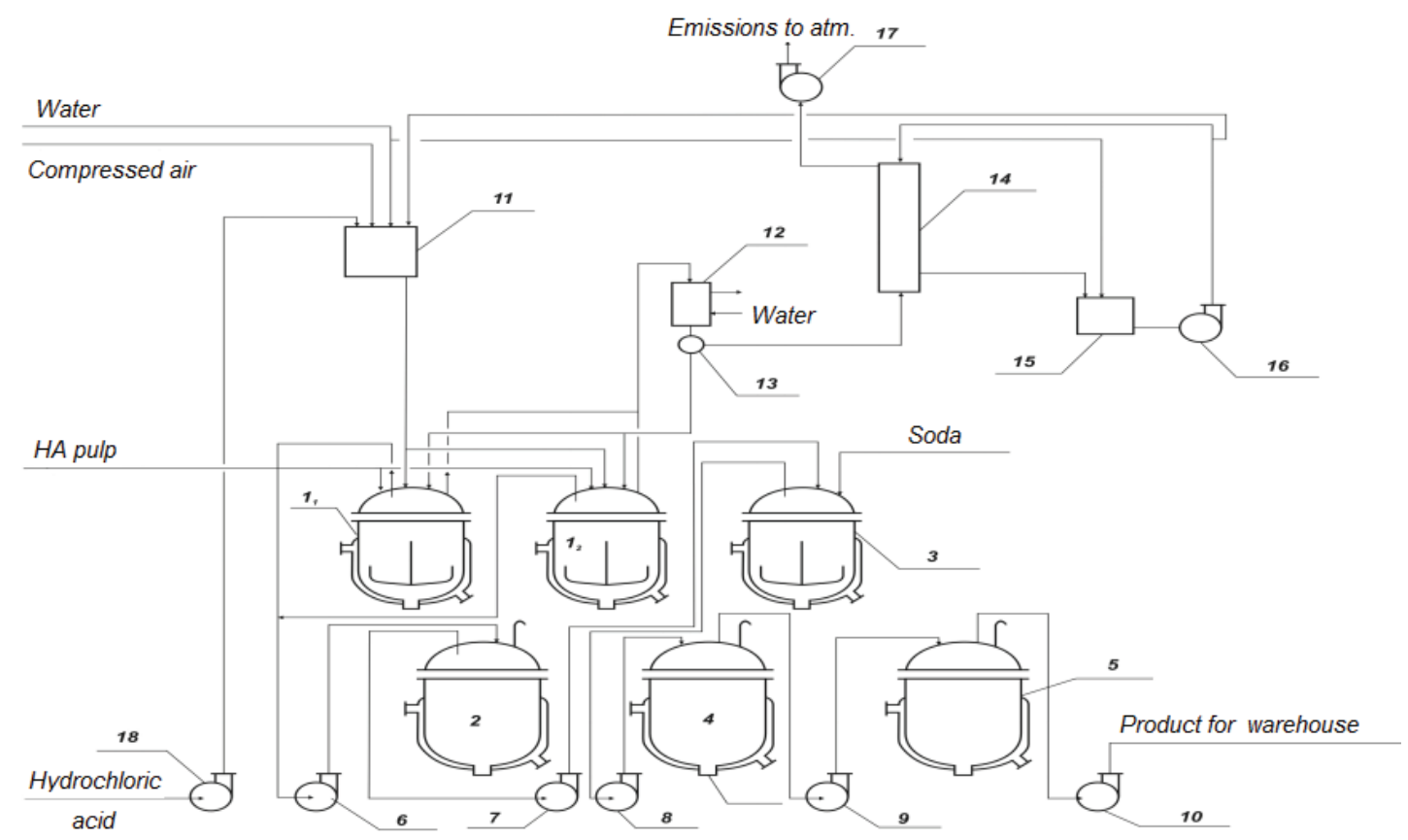

Figure 1: Apparatus for production of PAC from technical aluminium hydroxide and hydrochloric acid followed by neutralization with soda ash; $1_{1}, 1_{2}, 3,4$ - reactors; 2,5 - storage tanks; 6-10, 16-18 - pumps; 11 - gauge; 12 - heat exchanger-condenser; 13 - phase separator; 14 is an absorption column; 15 - circulation tank.

Since the working cycle of technical aluminum hydroxide dissolution is 12 hours, and the subsequent process of neutralization fits into 6-hours, followed by two hours exposure for polymerization, the production process can be organized as follows when using hydroxide precipitate. Reactors $1_{1}$ and $1_{2}$ are used for dissolving aluminum hydroxide, in 
TABLE 1: Comparative feasibility estimate for production of PAC from Technical Aluminium Hydroxide and Hydroxide Sludge.

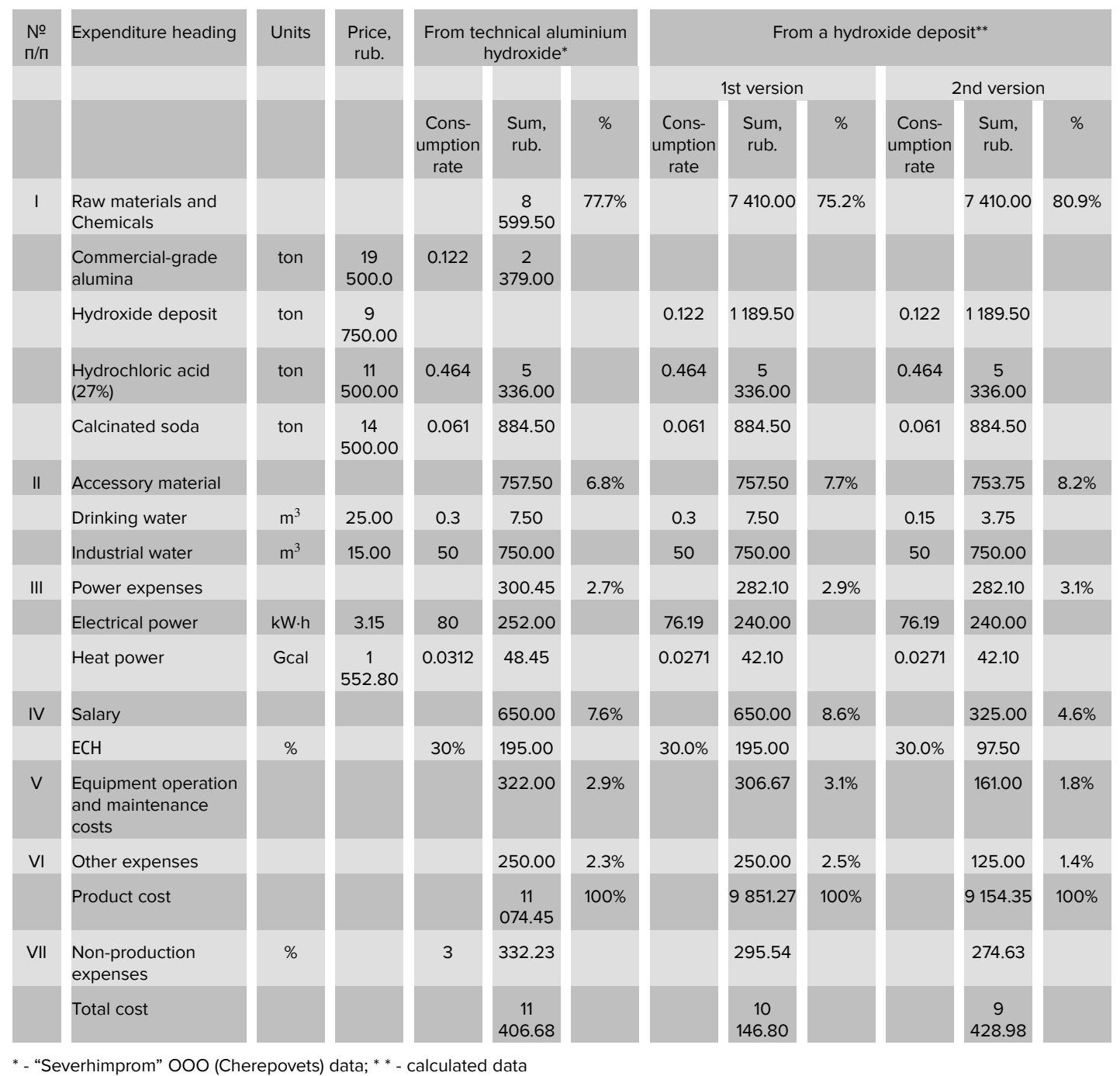

such a case while they operate so that procedures are offset by 6 hours. Due to such a shift the continuous charge of the reactor 3 is achieved (for deacidification). Subsequent technological operations are not limiting factors. Since the technical grade hydroxide is delivered with a stoichiometric excess with respect to $\mathrm{HCl}$, then its unreacted part is pumped into the storage tank 2 and further into the process oneset.

Since when using a hydroxide precipitate, the cycle of its dissolution in hydrochloric acid is reduced by half and there is no need for a stoichiometric excess of aluminum hydroxide, one can organize the work on the site using one of two versions.

- 1st version - without increasing HOAC production. Since the time cycle of dissolution and neutralization coincide, the balance of these processes can be achieved with a ratio of apparatus volumes 1: 1 at these stages. In this case, one of the reactors $1_{1}$ or $1_{2}$ can be decommissioned and the storage tank 2 will no longer need to be used. 
- 2nd version - with an increase in HOAC production. By equalizing the dissolution and neutralization cycles, it is possible to double the HOAC production. For this purpose, it is necessary to equip the storage vessel 2 with a stirrer and a neutralizing agent dispenser, after which it will be used as a reactor for neutralizing the acid solution of HOAC. As a result of the conversion, the process will look as follows. In each pair of reactors $1_{1}$ and 2 and $1_{2}$ and 3 , the aluminum hydroxide is dissolved successively and the HOAC is neutralized to the required basicity. The total time of the serial cycle will be 12 hours ( 6 hours for dissolution, 6 hours for neutralization). Further, the obtained HOAC must be kept in a 4 vessel for 2 hours to polymerize it. In order to avoid overlapping flows of parallel chains $1_{1}$ and 2 and $1_{2}$ and 3 in vessel 4 , they should be shifted in time relative to each other, for example, the loading of reactor $1_{1}$ should start 3 hours earlier than the loading of reactor $1_{2}$. According to the 1 version, the main reduction of prime cost is due to the use of twice cheaper waste as raw material than was used earlier in the technology of technical aluminum hydroxide. Also, by reserving one of the two reactors $\left(1_{1}\right.$ or $\left.1_{2}\right)$ used to dissolve aluminum hydroxide and storage tank 2 (see Figure 1), equipment maintenance and operation costs will be reduced by $3 \%$ and by accelerating the process of dissolving the hydroxide precipitate in hydrochloric acid, energy costs will be reduced by $11 \%$ overall. Total cost reduction for the 1st version:

$$
\mathrm{C}_{1 \text { tot }}=\left(\mathrm{C}-\mathrm{C}_{1}\right) / \mathrm{C} \cdot 100 \% \text {, }
$$

where $\mathrm{C}_{1 \text { tot }}$ - the total cost reduction for 1 version, \%; $\mathrm{C}$ - the cost of HOAC from technical aluminum hydroxide, rub per ton; $\mathrm{C}_{1}$ - the cost of HOAC from hydroxide precipitate according to the 1 version, rub per ton:

$$
C_{1 t o t}=(11406.68-10146.80) / 11406.68 \cdot 100 \%=11.0 \% .
$$

According to the 2 nd version, in addition to reducing the cost of the raw material component, due to doubling the volume of production in the same proportion, the conditional-permanent costs will be reduced. The total cost reduction for 2 nd version will be:

$$
\mathrm{C}_{2 t o t}=\left(\mathrm{C}-\mathrm{C}_{2}\right) / \mathrm{C} \cdot 100 \% \text {, }
$$

where $\mathrm{C}_{2 t o t}$ - the overall reduction in cost of the 2 nd version, \%; $\mathrm{C}_{2}$ - the cost of HOAC from a hydroxide precipitate according to the 2 nd version, rub.

$$
C_{2 t o t}=(11406.68-9428.98) / 11406.68 \cdot 100 \%=17.3 \% .
$$

Table 2 provides an estimate of capital investment in the conversion of the unreacted aluminum hydroxide vessel into a reactor to neutralize the HOAC solution. 
TABLE 2: Capital investments for refurbishment.

\begin{tabular}{|c|c|c|c|c|}
\hline No. & Item & Quantity & Price, rub. & Sum, rub. \\
\hline 1 & feeder & 1 & 250000 & 250000 \\
\hline 2 & mixer & 1 & 35000 & 35000 \\
\hline 3 & feed hopper & 1 & 25000 & 25000 \\
\hline 4 & other materials & & 50000 \\
\hline 5 & assembling (35\% from 1-4) & & 126000 \\
\hline
\end{tabular}

1. Payback period for capital costs for retrofitting due to additional cost reduction.

Annual savings from doubling HOAC production will be:

$$
\text { AS }=\left(C_{1}-C_{2}\right) \times V=\left(\begin{array}{lll}
10 & 146.80-9 & 428.98
\end{array}\right) \times 10=7178.2 \text { thousand rubles, }
$$

where AS - is annual savings, rub.; $\mathrm{C}_{1}$ - is HOAC cost price according to the 1st version, rub. per ton; $\mathrm{C}_{2}$ - is HOAC cost price according to the $2 \mathrm{nd}$ version, rub. per ton; $\mathrm{V}$ - is the volume of HOAC production according to the 2 nd version, thousand tons per year.

2. The payback period ( $T$, years) of capital investments for re-equipment will be:

$$
\mathrm{T}=\mathrm{K} / \mathrm{AS}=486: 7178.2=0.1 \text { years }=1 \text { month, }
$$

where $T$ - is payback period, years; $K$ - is the volume of capital investments for reequipment, thousand rubles; AS - is annual savings, rub.

$$
\mathrm{T}=486: 7178.2=0.1 \text { year }=1 \text { month } .
$$

Thus, a comparative techno-economic estimate of the cost of HOAC producing from technical aluminum hydroxide and hydroxide sludge showed that the cost of HOAC would be decreased by $11 \%$ by using a hydroxide precipitate. If the storage vessel is converted into a reactor to neutralize the acid solution of HOAC, the cost of operation on the hydroxide precipitate will decrease by $17.3 \%$ due to doubling the production of HOAC. Annual savings due to doubling of HOAC production volumes will amount to 7178.2 thousand rubles. The payback period for capital investments for retrofitting is 1 month.

\section{References}

[1] Tuzhilin, A. S., et al. (2014). Processing of Aluminium-Containing Slag and Hydroxide Precipitate to Obtain Alumina, Coagulants and Building Materials. Presented at Proceedings of the Congress "Basic Researches and Applied Developments of Processes of Processing and Utilization of Technogenic Educations". Yekaterinburg: Ural RAS. 
[2] Shut'ko, A. P., Sorochenko, V. F. and Kozlikovsky, Ya. B. (1984). Purification of Water with Basic Aluminium Chlorides. Kiev: Technika.

[3] Lainer, A. I., et al. (1978). Alumina Production. Moscow: Metallurgia.

[4] Lyakishev N. P., et. al. (2007). Method of producing aluminium hydroxochloride from technical aluminium hydroxide and hydrochloric acid. Patent RU2300499. 